\title{
Cough as a Cause and Consequence of Heart Dysfunction - Current State of Art
}

\author{
Elzbieta M. GRABCZAK ${ }^{1}$, Sebastian STEC ${ }^{2}$, Marta DABROWSKA ${ }^{1}$, Jana PLEVKOVA ${ }^{3}$, \\ Rafal KRENKE ${ }^{1}$
}

${ }^{1}$ Department of Internal Medicine, Pulmonary Diseases and Allergy, University Clinical Centre, Medical University of Warsaw, Poland, ${ }^{2}$ MediNice Research and Development Centre, Krosno, Poland, ${ }^{3}$ Department of Pathophysiology, Jessenius Faculty of Medicine in Martin, Comenius University Bratislava, Martin, Slovak Republic

Received October 5, 2019

Accepted November 25, 2019

\begin{abstract}
Summary
The cough reflex is an airway defensive process that can be modulated by afferent inputs from organs located also out of the respiratory system. A bidirectional relationship between cough and heart dysfunctions are presented in the article, with the special insights into an arrhythmia-triggered cough. Albeit rare, cough induced by cardiac pathologies (mainly arrhythmias) seems to be an interesting and underestimated phenomenon. This condition is usually associated with the presence of abnormal heart rhythms and ceases with successful treatment of arrhythmia either by pharmacotherapy or by radiofrequency ablation of arrhythmogenic substrate. The two main hypotheses on cough-heart relationships - reflex and hemodynamic - are discussed in the review, including the authors' perspective based on the experiences with an arrhythmia-triggered cough.
\end{abstract}

\section{Key words}

Cough • Cardiopulmonary reflexes • Arrhythmia

\section{Corresponding author}

Sebastian M. Stec, MediNice Research and Development Centre, ul. Korczynska 31, 38-400 Krosno, Poland. E-mail: smstec@wp.pl

\section{Introduction}

Cough is a defensive mechanism of the airways evoked by stimulation of nerve endings localized in larynx, trachea and main bronchi (Canning et al. 2014). It is also a common symptom of various pulmonary diseases. Even though cough is triggered exclusively by vagal reflex and is aimed at the airway defence, it can be elicited and modulated by afferent inputs from extrapulmonary organs, e.g. esophagus or external auditory canal (Canning et al. 2014, Widdicombe 1995), because the cough is related to stimulation of vagal afferents, irrespective of the organ localization (Widdicombe 1995). Although the vagal nerve plays a fundamental role in cough, the significance of convergence of other than vagal afferent inputs to the neuronal clusters in the brainstem - known as the cough pattern generator - cannot be ignored. These neuronal circuits are subjects of neuronal plasticity, where simple neuronal interaction or more complex neuroplastic relationships between vagal and other than vagal (e.g. trigeminal, glossopharyngeal) nerves modulate the final cough motor pattern (Canning et al. 2014).

Strong physiological interactions between respiration and heart function have been well described, including e.g. the alterations in sinus heart rhythm during breathing and the hypoxemia causing the increase in blood pressure and supraventricular arrhythmias in obstructive sleep apnea (Shepherd 1981, Shivkumar et al. 2016). Also, the impact of cough on heart hemodynamics associated with the robust changes of intraabdominal and intrathoracic pressure, influencing preload or afterload, is well known (Sharpey-Schafer 1953, Lo Mauro and Aliverti 2018). However, there is a number of case reports documenting an opposite relation, e.g. heart 
diseases, mainly arrhythmias, being a trigger of cough (Hargreaves and Channon 1994, Odeh and Oliven 1996, Niimi et al. 2005, Stec et al. 2007, Brandon 2008, Stec et al. 2009, Patberg et al. 2012, Hasdemir et al. 2013, Ozturk and Yetkin 2016). Although the prevalence of arrhythmia-related cough seems to be rather low, the mutual interactions have been recently recognized by national and international cough guidelines (Kardos et al. 2010, Irwin et al. 2018, Lai et al. 2018). Nonetheless, the mechanisms of heart disorder-related cough still remain not completely elucidated. Therefore, the main objective of this review is to discuss the available data on possible heart-cough relations. Both directions of the heart-cough interactions are reviewed. First, the effect of cough on heart function is presented and then, the mechanisms of "cardiac cough" or "cough triggered by heart function disorders" are discussed.

\section{Physiology of cough}

\section{Cough induced from airways}

There is indisputable evidence on the close relationship between cough and vagal nerve function. The vagotomy or vagal nerve cooling in animals completely abolishes cough (Canning et al. 2006). The bodies of the neurons innervating airways are located in the nodose and jugular ganglia of the vagal nerve (Mazzone 2005). Airway afferents relevant for cough are classified into mechano- and chemosensitive terminals depending on their activation profile. Airway mechanosensors are derived from the nodose ganglion and terminate in airways and lungs. These fibers have relatively fast conduction speed $(10-20 \mathrm{~m} / \mathrm{s})$ and their endings are classified as rapidly or slowly adapting receptors (RARs and SARs, respectively) based on the adaptation pattern to the lung inflation. The main stimuli for these receptors include lung volume changes, contraction of airway smooth muscles and the airway wall edema. These fibers participate in the regulation of breathing pattern, bronchomotor response and other reflex responses in the respiratory tract (Mazzone 2005, Widdicombe 1995). They are not sensitive to chemicals, unless these substances cause airway edema, increase mucus secretion or induce the changes in airway muscle tone. The role of RARs and SARs, as a structural elements of the cough reflex, is rather limited, they probably regulate the duration and magnitude of the inspiratory and expiratory phases of coughing but do not usually initiate the reflex itself (Canning et al. 2014).
Airway chemosensitive afferents (both $\mathrm{C}$ - and A-delta fiber subtypes) originate from the nodose and jugular ganglia and they are broadly distributed all over the airways and lungs. Airway chemosensors are activated by different endogenous and exogenous chemicals such as inflammatory mediators, oxidizing substances or air-born irritants (Canning and Chou, 2009). The unmyelinated C-fibers show low conducting velocity $(0.5-2.0 \mathrm{~m} / \mathrm{s})$. They comprise the majority of the afferent fibers innervating lungs. These include pulmonary C-fibers (with the endings located in the lungs and airways receiving blood perfusion from the pulmonary circulation) and bronchial C-fibers (with endings located in the larger bronchi receiving blood supply from bronchial arteries) (Lee and Pisarri 2001, Kollarik et al. 2010). C-fibers are rather inactive during the normal breathing cycle, but their activity increases significantly after exposure to noxious stimuli (Kollarik et al. 2010). C-fiber terminals are located between the epithelial cells covering the airways, close to the airway lumen. This arrangement allows the detection of irritants entering the airways and makes the C-fibers the perfect candidates for "cough-related afferents" (Canning et al. 2006). It has been demonstrated that activation of airway chemosensors is necessary for conscious perception of airway irritation, which mediates behavioral cough response (Davenport 2009). A-delta $(\mathrm{A} \delta$ ) fibers are myelinated afferents that exhibit both chemosensitive and mechanosensitive properties. They are extrapulmonary, low threshold and rapidly adapting fibers that conduct impulses faster than unmyelinated C-fibers, but slower than other A fiber subtypes. A $\delta$-fibers are sensitive mainly to the rapid decrease of $\mathrm{pH}$. As documented in animal studies, both $\mathrm{C}$ - and A $\delta$-fibers function synergistically to regulate cough (Canning 2010).

There is compelling evidence that cough reflex can be initiated from the larynx, trachea and the main bronchi. In contrast, there is no sufficient data on the presence of "cough receptors" in the peripheral airways. Therefore, the relationship between different conditions affecting the peripheral bronchi and alveoli and the cough is unclear (Widdicombe 1995). It has been documented that the pulmonary C-fibers (called juxta-pulmonary receptors or $\mathrm{J}$ receptors) are activated consistently by pulmonary congestion and edema, being sensitive to an increase in interstitial fluid volume, the elevated pressure in the lung or an increase in the fluid filtration across the capillary wall (Lee and Pisarri 2001). Noteworthy is the fact, that intravenous injection of lobeline (the substance 
believed to stimulate $\mathrm{J}$ receptors) in a higher dose resulted in "transient sensations involving the throat, larynx and upper chest", but also in cough (Raj et al. 1995, Gandevia et al. 1998). However, the conditions affecting mainly peripheral airways and vessels, such as pulmonary embolism, pneumothorax and pulmonary congestion are associated with dyspnea and chest tightness rather than cough (Sellick and Widdicombe 1969, Lee and Pisarri 2001, Kollarik and Brozmanova 2009). One of the reasons could be habituation of $\mathrm{J}$ receptors to the stimuli by chronic activation of vagal endings as discussed by Gandevia et al. (1998). Therefore, the role of $\mathrm{J}$ receptors in evoking cough still remains unresolved.

Airway afferent nerves provide the inputs to the brainstem. They conduct the signals to the second-order neurons in the nucleus of the solitary tract (nTS) and some of its subnuclei. Signalling from the airway sensors to the brainstem circuits is analyzed and processed by cough pattern generator, which in case of the relevant afferent stimuli replaces normal respiratory rhythm by a cough motor pattern (Rybak et al. 2008). Via activation of respiratory muscles, the motor cough response is executed with its typical three phases: 1) a deep inspiration (inspiratory phase) followed by 2) compression of the air in the thorax caused by contraction of the expiratory muscles and the closure of the glottis (compression phase) and finally by 3 ) the powerful forced expiration, which cleans the airways with characteristic sound (expulsion phase) (Brandimore et al. 2015).

\section{Cough induced from extrapulmonary organs}

Although the cough reflex is usually elicited from the airways, it can be initiated and modulated by stimuli generated outside of the pulmonary tract as well. The best documented connection between stimulation of extrapulmonary vagal nerve endings and cough was found for the vagal terminals in the esophagus. Regardless of the possibility of microaspiration of the acid aerosol as a trigger of cough, two more important mechanisms of this interaction are taken into consideration. These are a reflex interaction between esophageal and airway fibers generating cough, and sensitization of cough reflex due to activation of vagal nerve endings in the esophagus (Kollarik and Brozmanova 2009, Canning et al. 2014). The vagal nerve is believed to be the only route involved in this relationship since there are no proofs for the participation of spinal or cranial nerves. This might be consistent with the observations that patients with gastroesophageal reflux-related cough rarely report typical symptoms like heartburn, which are mediated by spinal pathways (Kollarik and Brozmanova 2009). Infusion of acid into distal esophagus was associated with increased capsaicin cough sensitivity (Javorkova et al. 2008). Therefore, among two types of vagal nerve endings detected in the esophagus, $\mathrm{C}$-fibers are believed to play the main role in triggering the cough and the role of esophageal mechanoreceptors is not clear (Kollarik and Brozmanova 2009). The second well-known example of the involvement of vagal nerve outside the respiratory system in coughing is the irritation of Arnold's nerve (a branch of the vagal nerve innervating external auditory canal) (Dicpinigaitis et al. 2018). Based on the data presented above we can assume that stimulation of vagal nerve terminals in the heart can also trigger cough, thus explaining the heart-cough relationship.

It's worth emphasizing that the signal from airway "cough receptors" can be modulated (enhanced or diminished) at any level of the neural pathway, including peripheral afferent parts, ganglia or even the central nervous system. An interesting concept of the convergence of afferent inputs to the nTS has been presented and then confirmed as a mechanism of coughing provoked by stimulation of vagal afferents outside the airways. Multiple vagal sensory nerves from different organs project to nTS and interact with other afferent inputs by either evoking cough or by modulating it. For example, stimulation of trigeminal afferents in the nose can either up-regulate or down-regulate cough response depending on the subpopulation of afferents which were stimulated (TRPA1 vs TRPM8 expressing afferents) (Buday et al. 2012). Afferent fibers from the heart also terminate in the nTS, therefore, there is a suitable platform for mutual anatomical and functional interaction between cardiac afferents and neurons that participate in the neurogenesis of cough.

\section{Innervation of the heart}

The heart is innervated via both parasympathetic (vagal nerve) and sympathetic fibers. These fibers form the cardiac plexus and they are situated close to the pulmonary trunk. It gives branches to the anterior pulmonary plexus, to the coronary plexus and directly to the heart affecting both atrial and ventricular function. Cholinergic motor control of the heart is widely distributed being concentrated in the sinoatrial nodal 
region and in the outflow tracts of each ventricle (Shivkumar et al. 2016). According to Shepherd (Shepherd 1985), there are 3 main types of afferent cholinergic nerve terminals in the heart. The first type is represented by myelinated vagal nerves that are located at the junction of the venae cavae with the right atrium and at the point of entry of pulmonary veins to the left atrium. The second type is unmyelinated afferent vagal nerves (C-fibers) that create a rich innervation network throughout the myocardium, pericardium, epicardium, interstitial and perivascular tissues. Finally, the third type is both myelinated and unmyelinated vagal afferents that are present throughout the heart chambers and project to the spinal cord with the sympathetic nerves. The nerves transduce mechanical and chemical stimuli through nodose ganglia as well as through the C6-T6 dorsal root ganglia to CNS (Shivkumar et al. 2016). The nerve terminals concentrating at the venous-atrial junctions react to the degree of atrial filling and project signals to the sinus node to alter heart rate and maintain a constant cardiac output. The C-fibers mainly respond to an increased volume of the heart. The mechanoreceptors accompanying spinal afferent nerves express the chemosensory properties and function as the polymodal afferents (Shepherd 1985). Sympathetic nerves project into the myocardium along with the parasympathetic innervation and together with sensory fibers act as the regulators of cardiac function (Kalla 2016).

The afferent fibers from the heart terminate in the nTS, which is a vital integrating center for the reflex control of cardiac function, circulation and respiration, according to the inputs received from the respiratory system, arterial baroreceptors and chemoreceptors and receptors in the skeletal muscles. The efferent nerves project to the cardiac vagal nuclei in the medulla, other nuclei in the brainstem and to the sympathetic preganglionic nuclei in the spinal cord and to other brain regions (Kalla 2016).

Interestingly, stimulation of the nerve endings of the heart can elicit variable response depending on the location of distinct pathologies. For example, ischemia affecting the right ventricle and left inferior ventricular wall (area innervated mainly by unmyelinated vagal $\mathrm{C}$ fibers) induces bradycardia and hypotension, while the same process affecting the anterior wall of the left ventricle with the higher density of the sympathetic nerve endings results in tachycardia and hypertension (Shepherd 1985). Moreover, stimulation of C-fibers in the heart may not only result in bradycardia and hypotension but also in apnea, what is known as BezoldJarish reflex and it documents the importance of vagal nerve in cardiopulmonary reflexes.

Branches of the vagal nerve also form a plexus around the pulmonary trunk, its bifurcation and the main pulmonary veins (Shepherd 1981). Therefore, it may be hypothesized that both heart chambers and pulmonary vessels may constitute a place of possible vagal nerve activation in heart dysfunction-related cough.

\section{The impact of cough on heart function}

Cough influences heart function either by its effects on intrathoracic pressure resulting in cardiovascular hemodynamic consequences or by influencing heart electrophysiology causing an arrhythmogenic effect. It is difficult to distinguish or separate these two phenomena due to their interplay (Fig. 1).

The impact of cough on the cardiovascular system has been documented in numerous previous studies, especially in the context of cough-induced arrhythmias, cough-induced conduction disorders or cough-induced syncope. However, controversies still exist on the role of cough in cardiopulmonary resuscitation. These conditions will be discussed below.

\section{Cough and its hemodynamic impact}

The deep and vigorous cough results in significant fluctuations in both intrathoracic and intraabdominal pressure, up to $250-450 \mathrm{mmHg}$ and 100 $\mathrm{mmHg}$, respectively. It may activate both thoracic pump mechanism (responsible for increased venous return and displacing blood from pulmonary veins into the left atrium) and abdominal pump, that enhances venous return and moves blood to other organs (Sharpey-Schafer 1953, Lo Mauro and Aliverti 2018). A decreased intrathoracic inspiratory pressure in the inspiratory phase leads to an increase in the right ventricle filling. It is worth mentioning, however, that excessively negative pressure in the thoracic cavity may yield in large vein collapse (Pappano and Wier 2013, Culver et al. 2008). During an expulsive phase of coughing, increased intrathoracic pressure compresses the heart and the large vessels and acts as an additional factor of blood ejection from the heart and its shift to the peripheral vessels (Lo Mauro and Aliverti 2018). In healthy subjects, the voluntary cough may cause a shift of a significant amount 


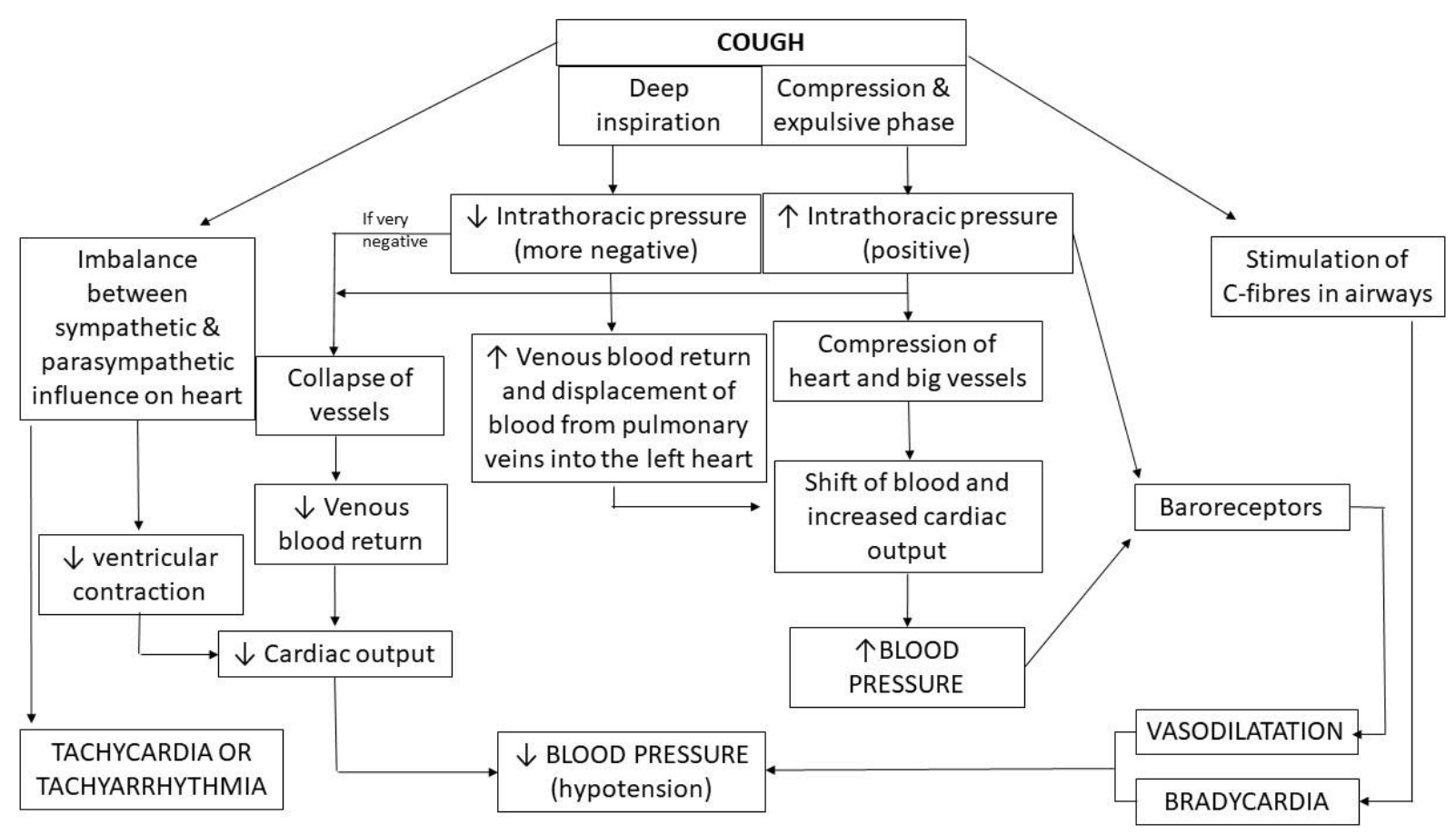

Fig. 1. Possible impact of cough on heart function

of blood (about $200 \mathrm{ml}$ during the compressive phase, and from 400 to $700 \mathrm{ml}$ during the expulsive phase) (Lo Mauro and Aliverti 2018) thus increasing the blood pressure. However, the situation changes shortly after cough termination.

Physiological studies documented that the intermittent coughing (when inspiratory effort follows each cough) is associated with a decline in blood pressure and peripheral vasodilatation after cough bouts (SharpeySchafer 1953). The increase of intrathoracic pressure during cough can cause both a decline in venous blood return and activation of baroreceptors with subsequent peripheral vasodilatation, eventually resulting in arterial hypotension. Marked peripheral vasodilatation may result in syncope, even if cardiac output remains unchanged or is even increased (Dicpinigaitis 2014). Additionally, high intrathoracic pressure during coughing may also be transmitted to the subarachnoid space, resulting in a reduction of cerebral blood flow, being another possible mechanism of syncope in a coughing patient. Interestingly, the intrathoracic pressure may remain elevated (6-10 $\mathrm{mmHg}$ ) for some seconds after cough, probably due to bronchoconstriction and air trapping during coughing. Therefore, it may additionally augment the hypotension observed after this motor act (SharpeySchafer 1953).

During continuous coughing, the circulatory effects are similar to Valsalva maneuver. Termination of the coughing bout is associated with the period of acute hypotension accompanied by peripheral vasoconstriction (Dicpinigaitis 2014). The best characterized clinical entity caused by the hemodynamic consequences of cough is a cough-induced syncope.

\section{Cough-induced syncope}

Cough-induced syncope is a reflex, transient loss of consciousness lasting for a few seconds due to an attack of strenuous cough. After the recovery, patients usually remember the beginning of cough bout (Brignole et al. 2018). There are many case series describing the cough syncope. Interesting data on this phenomenon were provided in the review by Dicpinigaitis et al. (2014). According to the literature analysis performed by the authors, cough syncope may account for $2.6 \%$ (range $0.9-4.2 \%$ ) of all syncope cases in adults. There is a significant predominance of men (about $92 \%$ ) affected, a frequent coexistence of obstructive pulmonary disease and a variety of the central nervous system disorders in the patients with cough syncope. It can be mild, with no serious consequences, however, cases of death due to cardiac arrest or fatal motor vehicle accidents during coughing episodes have also been reported (Dicpinigaitis et al. 2014). Therefore, it is recommended to avoid driving after the first episode of cough syncope until syncope is controlled by cough suppression therapy (Shen et al. 2017). 
The main mechanism responsible for the syncope seems to be a cough-induced reduction of the cerebral blood flow either due to a direct or indirect effect. A direct effect is a peripheral hypotension due to reduced venous return and cardiac output as a consequence of very high intrathoracic pressure during strenuous cough. An indirect effect refers to the increase in cerebrospinal fluid pressure causing brain hypoperfusion (Dicpinigaitis et al. 2014). Interestingly, male predominance and the concomitant obstructive airway disease suggest that the higher intrathoracic pressure generated during coughing may be relevant in cough syncope. An additional impact of neural reflex mechanism on vasodilatation should also be considered, due to the fact that the patients with cough syncope demonstrate more pronounced hypotension, inappropriate cough-triggered blood pressure-heart rate relationship and a slower recovery of blood pressure when compared to other syncope patients (Benditt et al. 2005).

\section{Cough and its effect on heart electrophysiology}

Although the primary role of the lung afferent nerve fibers is to modulate the breathing pattern (e.g. Hering-Breuer reflex), activation of some of their subpopulations also causes the reflex changes in the cardiovascular system (Shepherd 1981). For example, the stimulation of the pulmonary $\mathrm{C}$-fibers may result in bradycardia (beginning even with asystole) and systemic and pulmonary hypotension (Lee and Pisarri 2001, Canning et al. 2014). This vagal stimulation may entail a depression of automaticity of both the sinus and atrioventricular nodes, prolongation of the refractory period of the junctional tissues and depression of sinoatrial and atrioventricular conductivity (Irani and Sanchis 1971). These interactions are mainly related to parasympathetic activation, however coexisting withdrawal of sympathetic influence is also considered.

Besides the reflex bradycardia, a forceful cough may cause sinus tachycardia. Wei and Harris (1982) documented a chronotropic response to intrathoracic pressure changes generated by cough. In their study group, three forceful coughs performed over a period of 3 sec resulted in a reproducible increase in the rate of sinus rhythm (from mean 72 to 94 beats/min). This phenomenon was found to be dependent on patient's age, with an advanced age resulting in a decline in both the amplitude and rapidity of the chronotropic response of sinoatrial node to cough (Wei et al. 1983).

Interestingly, activation of the vagal nerve may also show an arrhythmogenic effect. The vagal stimulation may lead to the hyperpolarisation of the membrane, the depression of the phase 4 depolarization and the shortening of the duration of the action potential of atrial muscle cells as the result of increased outward potassium conductance (Omori et al. 1984). That may result in a more frequent occurrence of supraventricular ectopic beats (SVEBs) due to the enhanced excitability of the atria. This hypothesis seems to be supported by the effect of atropine and digitalis on arrhythmias in patients with cough-induced arrhythmia. As documented by Omori et al. (1984) the arrhythmia in those patients was inhibited by atropine and enhanced by intravenous administration of digitalis what additionally points to a vagotonic effect. Also, atrial fibrillation mediated by the vagal nerve is a well-known phenomenon (Omori et al. 1984).

If it is assumed that chronic cough may be associated with the increased vagal nerve excitability or its hypersensitivity, a potential impact of cough on parasympathetic innervation of the heart resulting in sinus bradycardia, advanced atrioventricular block, hypotension or even supraventricular arrhythmia cannot be excluded.

\section{Cough-triggered arrhythmias}

As presented above, the cough has an impact on different parameters of cardiac electrophysiology and may lead to disturbances in both impulse generation and conduction. Cough-induced arrhythmia, either atrial or ventricular, has been reported and supported by the observations of the close symptoms co-occurrence and arrhythmia resolution after vagal block or ablation.

Cough-triggered atrial arrhythmias: One of the first examples of arrhythmia, including a premature atrial and ventricular contractions (PACs and PVCs), related to coughing but also swallowing, speaking and other types of pharyngeal stimulation was described by Omori et al. (1984). The authors found no effect of different antiarrhythmic drugs (e.g. lidocaine, verapamil, digitals) except atropine on the occurrence of cough-related PACs. This finding proves the role of the vagal nerve in the pathogenesis of this type of arrhythmia.

Other examples are PACs and atrial tachycardia triggered by spontaneous or voluntary cough reported by Wang et al. (2017). The authors presented a case report of a patient with 2-year history of cough-induced palpitations that were unresponsive to conservative treatment. After ablation of the right-sided posteroinferior 
part of interatrial septum the cough-triggered arrhythmia vanished. The authors hypothesized that the mechanism of cough-triggered arrhythmia was a neural reflex, probably more vasovagal than adrenergic, due to lack of response to isoproterenol infusion. They suggested that cough may trigger a vasovagal reflex by increasing the right atrium pressure what strengthens the vagal tone. This could lead to the dispersion of atrial repolarization and favor the occurrence of micro-reentry in some specific parts of the atrium (Wang et al. 2017).

Cough-triggered ventricular tachycardia: Although the cough has been recommended as a tool for reversal of life-threatening ventricular tachyarrhythmias, some reports pointed towards an opposite situation, i.e. triggered by cough attacks ventricular tachycardia (VT) (Reisin et al. 1994). The example can be the coughinduced VT in a patient with a left ventricular assist device described by Ruckdeschel et al. (2016).

\section{Cough-triggered cardiac conduction disorders}

Besides an active heterotopy which manifests as PACs, PVCs, SVT or VT the conduction disturbances triggered by cough have also been reported.

Cough-induced sinus arrest: Sinus arrest as a result of voluntary or refractory cough of known or unknown origin was documented in two case reports (Choi et al. 1989, Aliyev et al. 2012).

Cough-induced atrioventricular (AV) block: The larger number of case reports presented cough-induced AV blocks, including Mobitz type II (Irani and Sanchis 1971, Baron and Huang 1978) and complete AV block (Irani and Sanchis 1971, Hart et al. 1982, Saito et al. 1982, Lee et al. 1999, Waldmann et al. 2017). In the majority of the reported patients, AV block was not triggered by other well-described maneuvers such as carotid sinus massage or interventions, e.g. intravenous administration of propranolol or irritation of baroreceptors with methoxamine-induced hypertension (Baron and Huang 1978, Saito et al. 1982). In only one case the AV block was reproducible during deep inspiration, Valsalva maneuver and coughing (Irani and Sanchis 1971). The significance of cough-induced vagal activation was demonstrated by intravenous administration of atropine that resulted in a complete cessation of cough-induced sinus arrest or suppression of AV conduction (Saito et al. 1982, Aliyev et al. 2012). The authors hypothesized that AV conduction disturbance may be associated with hypersensitivity of bronchopulmonary receptors to cough resulting in excessive stimulation of the vagal nerve. Animal studies showed that both a baroreflex and a broncho-pulmonary reflex may cause AV block when the sinus node is incapable to slow down appropriately during stimulation what can be observed during e.g. atrial fibrillation (Saito et al. 1982).

Cough-induced conduction disturbances can lead to syncope. There are some case reports on coughinduced, paroxysmal, complete or partial AV block with ventricular asystole (Irani and Sanchis 1971, Baron and Huang 1978, Hart et al. 1982, Saito et al. 1982, Lee et al. 1999, Waldmann et al. 2017) or sinus arrest (Aliyev et al. 2012) resulting in syncope or presyncope. The mechanism of this phenomenon is probably associated with a hypersensitive bronchopulmonary reflex during coughing that induces a complete AV conduction block. Premature ventricular contractions that evoked cough and syncope have also been reported (Stec et al. 2007). However, the causal relationship between the syncope and PVCs or the syncope and PVC-induced cough was not fully elucidated in that case.

\section{Cough and cardiopulmonary resuscitation (cough-CPR)}

It has been shown that significant intrathoracic and intraabdominal pressure swings associated with a forceful coughing may affect a maintenance of blood flow during unstable cardiac rhythm, e.g. ventricular fibrillation, asystole or even bradycardia and hypotension that may occur after intracoronary injections of contrast medium (Wei et al. 1980, Reisin et al. 1994, Lo Mauro and Aliverti 2018). Furthermore, it was estimated that cough may generate approximately 1 to $25 \mathrm{~J}$ of kinetic energy, which is sufficient enough to even convert the arrhythmia by its effect on cardiac depolarization (Reisin et al. 1994, Girsky and Cirley 2006). Therefore, it was suggested, that cough could be an easy and successful form of "cardiac massage" due to the intrathoracic pressure fluctuations maintaining enough blood flow to the brain allowing for patient's consciousness up to 90 seconds until the arrhythmia is treated (Lo Mauro and Aliverti 2018, Trethewey 2018). Despite a few case reports describing a positive effect of cough in patients with unstable cardiac rhythm and potential impact of cough on maintaining blood pressure, the procedure has not been recommended by guidelines as a form of traditional CPR (American Heart Association 2019, Resuscitation Council 2019) and is even considered possibly harmful by some authors (Trethewey 2018, McLachlan et al. 2007, Resuscitation Council 2019). 


\section{Heart diseases and their impact on cough}

To date, neither animal nor human studies provided data for sufficient explanation of the mechanism behind cough induced by heart disorders. "Cardiac cough" and hypotheses on its pathogenesis are based on careful clinical observations of patients with arrhythmias who also presented with a chronic cough which resolved after successful pharmacotherapy or radiofrequency ablation with the restoration of normal cardiac rhythm.
In general, two main mechanisms have been postulated which may trigger cough in patients with heart function disorders. The first one points towards the reflex interactions between heart afferent nerves and cough neural pathways, while the second mechanism is based on hemodynamic changes in lung circulation caused by heart dysfunction. It is important to note that in some cases it may be impossible to distinguish these two mechanisms, e.g. in arrhythmia-induced cough. The hypothetical mechanisms of "cardiac cough" are depicted in Fig. 2.

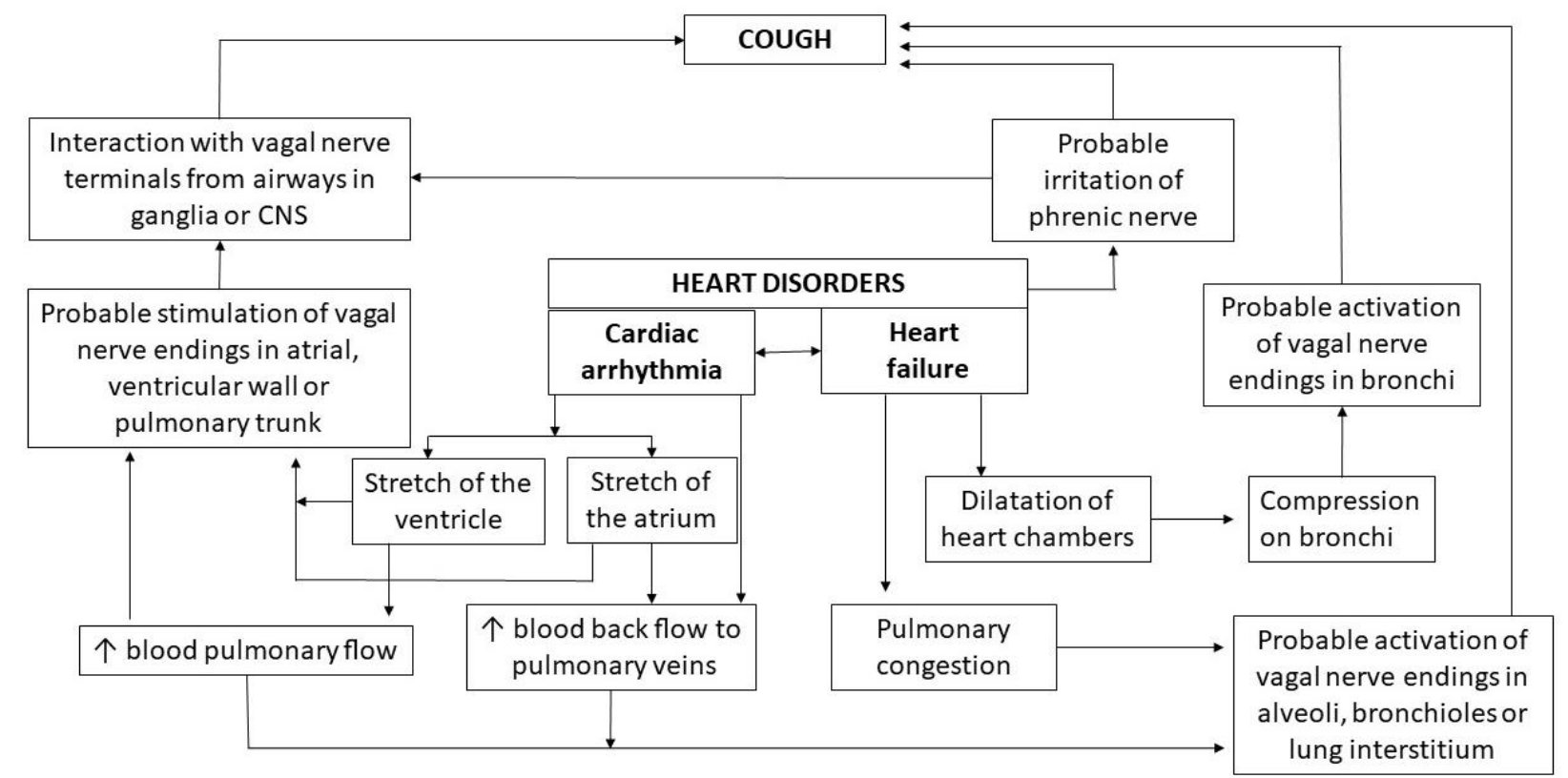

Fig. 2. Possible mechanisms of heart dysfunction-induced cough

\section{Neural reflex hypothesis}

The common vagal innervation of heart and airways provides a perfect background for cardiopulmonary or cardiothoracic reflexes. Moreover, previously presented examples of cough evoked by stimulation of the extrapulmonary vagal nerve terminals provide a reasonable basis to perceive vagal reflex as the main mechanism of cough induction by heart diseases. Hence, it has been hypothesized that stimulation of cardiac vagal nerve endings may interact with impulses from the respiratory system or it may act centrally at the level of nTS and neighbouring areas promoting enhanced cough responsiveness (Canning et al. 2014). It should also be considered that cough neural pathways could be affected either by activation of vagal nerve endings in the heart itself or its afferents in the main pulmonary vessels. Herein, the nerve terminals can be activated by the reverse blood flow to the pulmonary veins resulting in transient lung congestion or by increased blood flow into the pulmonary trunk and its bifurcation. Irritation of phrenic nerve based on its anatomical proximity cannot be excluded as well.

Pachon et al. (2005) demonstrated that the parasympathetic afferent fibers are present within the coronary sinus ostium, crista terminalis and interatrial septum areas. The endocardial radiofrequency ablation (RFA) of these areas is frequently performed as a treatment option for patients with vagal nerve mediated paroxysmal sinus bradycardia and/or atrioventricular blocks. Interestingly, in some patients with atrioventricular nodal reentry tachycardia (AVNRT), both tachyarrhythmia and cough episodes can be induced simultaneously during the invasive electrophysiological studies (EPS). These patients are usually sensitive and prone to suffer from cough episodes during ventricular pacing, junctional rhythms and fast atrial pacing mimicking AVNRT. In some cases, cough episodes disappear after RFA, although the arrhythmia itself persists and the further additional applications or the second procedure is essential to terminate the arrhythmia 
itself (personal observation). Based on these observations, we may speculate that RFA leads to the changes in the cardiac autonomic innervation and decreased parasympathetic nerve activity. Perhaps, the destruction of the epicardial postganglionic cells of the vagal nerve caused by RFA leads to cough resolution triggered by the arrhythmia. The destruction of the parasympathetic fibers seems to be more pronounced and more persistent than the destruction of postganglionic sympathetic axons because parasympathetic postganglionic cell bodies are situated directly in the heart ganglia, close to the myocardial wall and aorta (Shivkumar et al. 2016).

Furthermore, irritation of the phrenic nerve as possible afferent signalling pathway of the cardiac cough reflex should also be considered. The right phrenic nerve is located in close proximity to both atria and pulmonary veins. Its proximity to cardiac structures, as well as the fact that it supplies sensory fibers to the pericardium, could explain phrenic nerve stimulation e.g. by atrial contractions or transcatheter EPS interventions on the atrium or around the pulmonary veins (Brandon 2008). High output pacing of the phrenic nerve is an obligatory maneuver to check its individual epicardial location prior to and sometimes during the catheter ablation. Such pacing results in fast contraction of the diaphragm that is associated with cough in some patients. On the other hand, the cough may be one of the symptoms presented by patients with phrenic nerve injury during catheter ablation (Sacher et al. 2006). However, the literature data regarding this issue is scarce.

Stec et al. (2009) found that in patients with cough triggered by PVCs, the cough appeared not only immediately after PVC but also after the changes in heart frequency. Therefore, the influence of changes in sympathetic and parasympathetic tone balance should be considered as a potential mechanism for triggering cough.

Finally, the importance of the neural network in medulla oblongata should be particularly emphasized. The proximity of autonomic centers in the medulla oblongata, regulating respiration and cardiac function may predispose to centrally-mediated interactions and signal transmission among neural circuits influencing regulation of parasympathetic or sympathetic outflow with direct impact on cough or heart function. Interestingly, abnormalities in that region, e.g. medullary infarction, may cause simultaneously cough, bradycardia and syncope (Takazawa et al. 2014).

\section{Hemodynamic hypothesis}

Heart dysfunction, including arrhythmias and heart failure, may result in hemodynamic changes in both the heart chambers and the pulmonary circulation. These changes are construed as the possible stimuli for vagal afferents that can elicit the cough reflex. For example, the ectopic beats in PVCs, and probably less likely supraventricular extra beats (SVEBs) are associated with the increased blood flow in the pulmonary trunk due to the higher ejection volume after the compensatory pause. It can cause vessel wall distention and stimulation of vagal nerve endings located in the pulmonary arteries or within the plexus surrounding the pulmonary trunk. Niimi et al. (2005) demonstrated an increase in the pulmonary artery flow volume from 65 to $91 \mathrm{ml} / \mathrm{s}$ after PVCs in patients with arrhythmia-induced cough. Similarly, Hasdemir et al. (2013) reported an increase in systolic pulmonary artery pressure caused by PVCs during continuous-wave Doppler echocardiography (from 33 to $39 \mathrm{mmHg}$ ) and the change in blood flow velocity from 2.5 to $2.8 \mathrm{~m} / \mathrm{s}$. In the paper by Niimi et al. (2005), PVCinduced mitral regurgitation flow was also observed but as it was insignificant, the authors found it rather unlikely that PVC-induced changes in the left atrium could trigger cough.

Stec et al. (2007) documented that PVCs evoking cough were associated with the augmentation of peak flow velocity, as well as stroke volume, in the right ventricular outflow. However, a decreased velocity-time integral and stroke volume in left ventricular outflow by about $25 \%$, without any reverse flow to the pulmonary veins, strongly suggested no role for intermittent pulmonary venous congestion (Stec et al. 2007). Moreover, the backflow of blood, observed after PVC during mitral valve closure, could also stimulate parasympathetic receptors in the atrial wall and pulmonary veins.

Although in the case presented by Stec et al. (2007), the possibility of intermittent lungs congestion during arrhythmia-induced cough was discussed as unlikely, the question remains rather unsettled. The pulmonary venous congestion seems to be a probable mechanism of cough triggered by heart dysfunction due to both heart failure and arrhythmia. Left atrial pressure (LAP) increase is one of the major hemodynamic effects of ectopic beats. This may result in bronchial venous congestion or changes of the bronchomotor tone stimulating RARs or SARs. Studies in dogs showed that even a small $(5 \mathrm{mmHg})$ increase in LAP persisting for at 
least 1-minute evoked a profound response of RARs. This scenario was emphasized by Hargreaves and Channon (1994), who reported a patient with an occasional cough caused by VVI pacing with retrograde atrial conduction or atrial-ventricular asynchronous, nonphysiological pacing mode. Although the intraatrial pressure was not measured, the authors suggested that the increase in LAP was an important factor influencing the RARs' activity. This seems to be consistent with a fact that cough reflex was augmented in a supine position of that patient (Hargreaves and Channon 1994). The same mechanism could be involved in a patient reported by Hadsemir et al. (2013), in whom cough was related to transient left ventricular hypokinesis caused by PVCs. Also, Sakihata et al. (2019) presented a case of a patient with tachycardia-induced cardiomyopathy presenting symptoms of heart failure and cough. Although the hypothesis of pulmonary congestion as a cause of cough seems reasonable, from the physiological perspective it remains doubtful, whether bronchiolar or alveolar irritation could evoke cough (Widdicombe 1995), unless there is underestimated role of $\mathrm{J}$ receptors. Interstitial pulmonary edema can stimulate pulmonary and bronchial vagal afferents resulting in dyspnea or chest discomfort. It has been suggested that the presence of fluid in the alveolar or interstitial spaces is not able to trigger cough in patients with pulmonary edema unless the amount of fluid is sufficient to penetrate the main bronchi and activate local "cough receptors". The most current guidelines for the diagnosis and treatment of acute and chronic heart failure of the European Society of Cardiology list nocturnal cough as a "less typical" sign of chronic heart failure (Ponikowski et al. 2016). Patients with heart failure report more often exercise intolerance, dyspnea and peripheral edema, while cough is considered to be only a minor sign.

An additional mechanism of cough induced by cardiomegaly or enlarged left atrium has also been proposed. Based on the animal studies, cardiomegaly with marked left atrial (LA) dilatation may cause a compression of main bronchus resulting in stimulation of cough receptors and "cardiac cough". Nevertheless, it has been suggested that LA dilatation and LA pressure alone may not be sufficient to cause cough secondary to compression of the trachea and the main bronchi without a concomitant underlying tracheobronchial disease, e.g. bronchomalacia or chronic bronchitis (Ferasin and Linney 2019).

Characteristics and examples of cough triggered by

\section{cardiac arrhythmias}

Patients with arrhythmia-triggered cough report mainly dry cough (Hasdemir et al. 2013, Odeh and Oliven 1996, Ozturkt and Yetkin 2016). It is usually not very intense, but persists throughout the day and night, resulting in sleep disruption not only in patients with coexisting heart failure. According to the subjective patients' opinion, the severity of PVC-triggered cough decreases at night (Stec et al. 2009). Some patients report palpitations and exertional dyspnea (Omori et al. 1984) but others deny any coexisting signs and symptoms (Odeh and Oliven 1996, Ozturk and Yetkin 2016).

Patients describe the cough as a reflexive, sudden need to cough preceded by a tickling sensation in the throat or a "thump" in the chest (Brandon 2008, Stec et al. 2009). The cough sometimes resembles expiration reflex - rapid expulsion of air from lungs without previous inspiration. Both single cough episodes and bouts of typical cough (cough preceded by deep inspiration) were reported.

Interestingly, in some patients with PVCinduced cough, arrhythmia was the only known cause of cough (Niimi et al. 2005, Odeh and Oliven 1996, Stec et al. 2007), while in others it was only a coexisting cause (Stec et al. 2009). What is important, cough reduction after antiarrhythmic treatment was so significant that no other cough-suppressing therapies were required.

In the group of 6 patients with PVC-induced cough described by Stec et al., arrhythmia recurred after a few months in 2 patients treated with RFA and in 1 treated with propafenone. In two of those patients also recurrence of cough was observed, and in one subject only concomitant exertional dyspnea was reported. RFA was reperformed with the resolution of both arrhythmia and concomitant symptoms (Stec et al. 2009).

\section{Premature atrial complexes (PAC)-triggered cough}

PAC is one of the most common arrhythmia that usually does not produce any symptoms. In 1996, Odeh and Oliven described a patient with 15-year-history of cough due to frequent unifocal PACs. A detailed diagnosis and application of different cough suppressing therapies were found ineffective. A significant decline in the number and severity of both PACs and cough was noticed only after treatment with high doses of propranolol. A similar case of the patient with 3-yearhistory of paroxysmal cough, both nocturnal and daytime, was presented by Ozturk and Yetkin (2016). Based on time relationship between PAC and subsequent cough, 
first noticed during echocardiography and then confirmed in ECG Holter monitoring, metoprolol was administered with marked reduction of cough bouts. The occurrence of cough immediately after palpitation in 3 patients with PACs was reported by Brandon (2008), who stated that PAC-triggered cough may be more frequently observed in cardiologists' practice than it's published.

\section{Premature ventricular contractions (PVC)-triggered cough}

Hasdemir et al. (2013) described a patient with idiopathic, frequent, monomorphic PVCs presenting with a 1-year history of dry cough and tachycardia-induced cardiomyopathy. A thorough diagnostic workup excluded the most frequent cough causes as well as heart diseases, except decreased cardiac ejection fraction due to tachycardia-induced cardiomyopathy. After initiation of antiarrhythmic treatment not only arrhythmia disappeared and an ejection fraction of the left ventricle has significantly improved, but also cough has completely resolved. In this case, cough reappeared during infection when arrhythmia was also observed and disappeared after the resolution of infection and termination of drugs containing pseudoephedrine.

A similar connection was earlier reported by Niimi et al. (2005) who treated a patient with single unifocal PVCs followed by cough episodes. The symptoms resolved after initiation of antiarrhythmic treatment with disopyramide. Two-dimensional color echocardiography revealed a small PVC-induced regurgitation flow to the left atrium and continuous wave Doppler echocardiography similarly presented a PVCinduced transient increase in the calculated pulmonary artery blood flow.

In the experience of our interdisciplinary group, the first case of PVC-induced cough was additionally associated with syncope (Stec et al. 2007). The clinical presentation included very frequent cough episodes reported only during 2 hours of very frequent PVCs without any PVCs and cough episodes during the rest of the ECG monitoring. In contrast to unsuccessful attempts of treatment with different antiarrhythmic agents, the RFA was found highly efficient in terms of treatment of both PVCs and subsequent cough and syncope. In order to assess the prevalence of PVC-induced cough, Stec et al. (2009) evaluated the group of 120 patients with PVCs. The cough was reported by 10 patients, but the temporal relationship between arrhythmia and cough was documented in only six of them $(5 \%)$. All these patients were women, and the mean cough duration was approximately 18 months. PVC-triggered coughing occurred repetitively and not only immediately after PVCs, as reported by Niimi et al. (2005) but also a few seconds later and appeared after changes in heart rhythm frequency (Stec et al. 2009).

Patberg et al. (2012) reported that arrhythmiainduced cough is a rare cause of unexplained chronic cough. In 7 patients with unexplained chronic cough and history of palpitation (with documented ventricular or supraventricular ectopic focus), no temporal relationship between arrhythmia and cough episodes was observed during the 12-hours simultaneous recording of ECG, nasal flow and chest and thorax movements. However, in one patient with a ventricular pacemaker, the stimulation induced cardiac arrhythmia with a subsequent cough. According to our experience (unpublished data), other heart rhythm disorders may also evoke cough. We observed paroxysmal AVNRT and focal atrial tachycardia causing paroxysmal cough. Both tachycardia and cough were cured by RFA.

\section{Pacemaker-triggered cough}

A single-chamber ventricular permanent pacing may cause different symptoms known as pacemaker syndrome, however, the cough might be its symptom only rarely. Hargreaves and Channon (1994) presented a patient with a tickling sensation in the throat and occasional cough since pacemaker insertion. The cough aggravated during short-term ventricular pacing during routine pacemaker check-up. Patberg et al. (2012) also recorded cough events during ventricular stimulation in pacemaker patient. Moreover, intermittent pacemakerinduced cough due to loss of physiological pacing in DDD patient and right ventricle and atrial infarction was reported by Kryński et al. (2007). The sensing and pacing of the atria led to recovery after reperfusion therapy and rehabilitation with spontaneous resolution of cough episodes (Kryński et al. 2007).

\section{Brief recommendations on the diagnosis and treatment of "cardiac cough"}

We present some useful methods for diagnostic workup in patients with "cardiac cough" and give some suggestions for treatment of this phenomenon below. This advice is based on both our own experience and the literature review.

Methods of "cardiac cough" diagnosing: The 
vast majority of patients with arrhythmia-induced cough do not present any auscultatory abnormalities or radiographic signs suggesting pulmonary congestion (Hasdemir et al. 2013). The first symptom from the medical history that may suggest arrhythmia-triggered cough is palpitation reported by the patient (Niimi et al. 2005, Hasdemir et al. 2013). Also, the occurrence of cough not only during the day but also at night may be valuable information (Odeh and Oliven 1996, Niimi et al. 2005, Hasdemir et al. 2013). Arrhythmia may be detected for the first time during the physical examination and then documented in ECG and/or Holter ECG recordings. However, its presence is not sufficient enough to prove the relationship between arrhythmia and cough. A crucial diagnostic clue is the timing of cough occurrence just after the premature beats. This connection can be confirmed when examining the patient's pulse (Odeh and Oliven 1996, Stec et al. 2009), performing an ECG (Niimi et al. 2005, Stec et al. 2007, Stec et al. 2009), echocardiography or rhythm Holter monitoring together with simultaneous cough recording (Ozturk and Yetkin 2016, Stec et al. 2007). Another medical device, that might be used to show time relationship between arrhythmia and cough, is a portable, multichannel recorder developed for sleep breathing disorders (cough is depicted as sudden changes in chest and abdomen movements and flow through nasal cannula) (Stec et al. 2007, Stec et al. 2009, Patberg et al. 2012) (Fig. 3). It can be also registered during the invasive electrophysiological study without general anesthesia. In patients with pacemakers, manual validation of pacing parameters and intermittent non-physiological pacing setting with programmer may reveal cough episodes.

The indisputable evidence for a relationship between arrhythmia and cough is a complete resolution of both arrhythmia and cough as the effect of antiarrhythmic treatment and the recurrence of cough when arrhythmia or non-physiological pacing reappears (Hasdemir et al. 2013). The ratio of arrhythmia-to-cough number, that may indicate its direct relation and not just mere coincidence, is not yet established. Tachyphylaxis should also be considered and it makes this diagnosis more challenging.

Therapeutic strategy in "cardiac cough": The response to antiarrhythmic treatment in patients with a cardiac cough is diverse. The authors of some case reports demonstrated the effectiveness of antiarrhythmic treatment not only in terms of heart rhythm but also in terms of complete resolution of coexisting cough. The antiarrhythmic interventions, that were found to be effective, included pharmaceuticals, e.g. propafenone (Hasdemir et al. 2013, Stec et al. 2009) and disopyramide (Niimi et al. 2005), as well as RFA ablation (Stec et al. 2007, Stec et al. 2009). However, in other cases betablockers (Hasdemir et al. 2013, Odeh and Oliven 1996, Stec et al. 2007), calcium channel blockers or propafenone (Stec et al. 2007), mexiletine and other antiarrhythmic agents (Niimi et al. 2005, Odeh and Oliven 1996) were found ineffective in restoration of

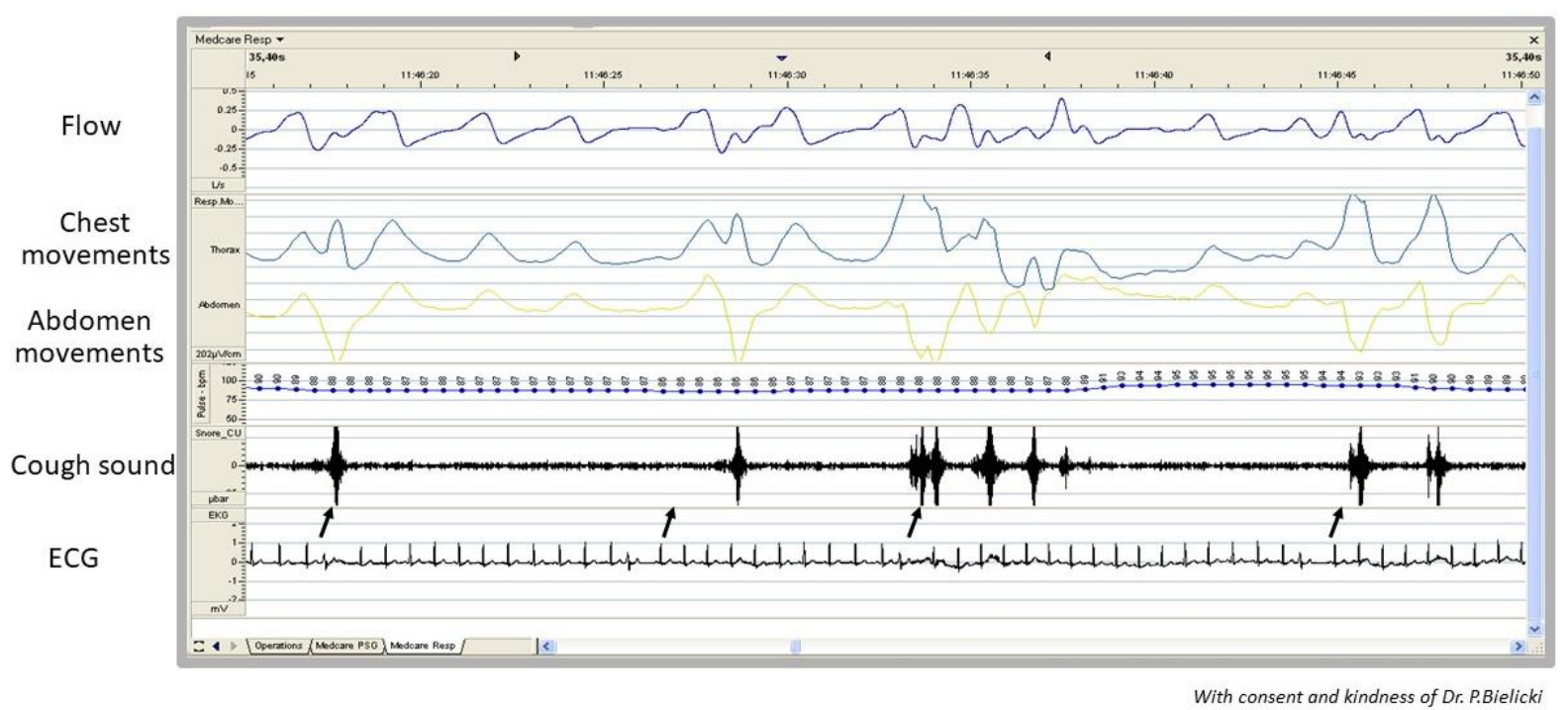

Fig. 3. Example of simultaneous record of nasal flow, chest and abdomen movements and ECG in a patient with arrhythmia-induced cough (possible connection between episodes of PACs and coughs marked with black arrow) 
normal heart rhythm and resolution of cough. Of six patients with PVC-induced cough reported by our group (Stec et al. 2009), antiarrhythmic agents were effective in only one patient, four patients were successfully treated with RFA, while spontaneous remission of arrhythmia and cough was observed in one patient. Hence, in our opinion, the data are too scarce to recommend the specific therapy of choice for patients with arrhythmiainduced cough.

\section{Conclusions}

The anatomical and physiological bases, as well as numerous case reports on patients with arrhythmiatriggered cough and cough-related cardiovascular conditions, confirm deep, mutual relationships between cough and heart function. The prevalence of those conditions is rather low and their mechanism still remains debatable. Based on our own experience and the literature data, we suppose that the dissemination of knowledge on the cough-heart relationships may result in a more common diagnosis and change of our view on a low prevalence of these conditions. Even if the prevalence of these syndromes will remain low, we still believe that a proper diagnostic and therapeutic approach may allow to significantly reduce the complaints among the patients with refractory chronic cough and arrhythmia. In our opinion, the topic is intriguing and warrants further, more systematic studies on the prevalence, pathophysiology and treatment of cough as the manifestation of heart function disturbances.

\section{Conflict of Interest}

There is no conflict of interest.

\section{References}

ALIYEV F, KILIÇKESMEZ KO, ÇELIKER C, TÜRKOĞLU C: Cough-induced sinus arrest resulting in recurrent episodes of syncope: is it really transient? J Cardiovasc Med (Hagerstown) 13: 468-470, 2012. https://doi.org/10.2459/jcm.0b013e32833892c4

American Heart Association. Cough CPR [Accessed 22 September 2019] https://www.heart.org/en/healthtopics/cardiac-arrest/emergency-treatment-of-cardiac-arrest/cough-cpr

BARON SB, HUANG SK: Cough syncope presenting as Mobitz type II atrioventricular block--an electrophysiologic correlation. Pacing Clin Electrophysiol 10: 65-69, 1978. https://doi.org/10.1111/j.1540-8159.1987.tb05925.x

BENDITT DG, SAMNIAH N, PHAM S, SAKAGUCHI S, LU F, LURIE KG, ERMIS C: Effect of cough on heart rate and blood pressure in patients with "cough syncope". Heart Rhythm 2: 807-813, 2005. https://doi.org/10.1016/j.hrthm.2005.04.022

BRANDIMORE AE, TROCHE MS, HUBER JE, HEGLAND KW: Respiratory kinematic and airflow differences between reflex and voluntary cough in healthy young adults. Front Physiol 6: 284, 2015. https://doi.org/10.3389/fphys.2015.00284

BRANDON N: Premature atrial contraction as an etiology for cough. Chest 133: 828, 2008. https://doi.org/10.1378/chest.07-2059

BRIGNOLE M, MOYA A, DE LANGE FJ, DEHARO JC, ELLIOTT PM, FANCIULLI A, FEDOROWSKI A, FURLAN R, KENNY RA, MARTÍN A, PROBST V, REED MJ, RICE CP, SUTTON R, UNGAR A, VAN DIJK JG. ESC Scientific Document Group: 2018 ESC Guidelines for the diagnosis and management of syncope. Eur Heart J 39: 1883-1948, 2018. https://doi.org/10.5603/kp.2018.0161

BUDAY T, BROZMANOVA M, BIRINGEROVA Z, GAVLIAKOVA S, POLIACEK I, CALKOVSKY V, SHETTHALLI MV, PLEVKOVA J: Modulation of cough response by sensory inputs from the nose - role of trigeminal TRPA1 versus TRPM8 channels. Cough 8: 11, 2012. https://doi.org/10.1186/1745-9974-8-11

CANNING BJ, MORI N, MAZZONE SB: Vagal afferent nerves regulating the cough reflex. Respir Physiol Neurobiol 152: 223-242, 2006. https://doi.org/10.1016/j.resp.2006.03.001

CANNING BJ, CHOU YL: Cough sensors. I. Physiological and pharmacological properties of the afferent nerves regulating cough. Handb Exp Pharmacol 187: 23-47, 2009. https://doi.org/10.1007/978-3-540-79842-2_2

CANNING BJ: Afferent nerves regulating the cough reflex: mechanisms and mediators of cough in disease. Otolaryngol Clin North Am 43: 15-25, 2010. https://doi.org/10.1016/j.otc.2009.11.012 
CANNING BJ, CHANG AB, BOLSER DC, SMITH JA, MAZZONE SB, MCGARVEY L, CHEST EXPERT COUGH PANEL: Anatomy and neurophysiology of cough: CHEST Guideline and Expert Panel report. Chest 146: 1633-1648, 2014. https://doi.org/10.1016/j.chest.2016.03.014

CHOI YS, KIM JJ, OH BH, PARK YB, SEO JD, LEE YW: Cough syncope caused by sinus arrest in a patient with sick sinus syndrome. Pacing Clin Electrophysiol 12: 883-886, 1989. https://doi.org/10.1111/j.15408159.1989.tb05024.x

DAVENPORT PW: Clinical cough I: the urge-to-cough: a respiratory sensation. Handb Exp Pharmacol 187: 263-276, 2009.

DICPINIGAITIS PV, LIM L, FARMAKIDIS C: Cough syncope. Respir Med 108: 244-251, 2014.

DICPINIGAITIS PV, KANTAR A, ENILARI O, PARAVATI F: Prevalence of Arnold nerve reflex in adults and children with chronic cough. Chest 153: 675-679, 2018. https://doi.org/10.1016/j.chest.2017.11.019

FERASIN L, LINNEY C: Coughing in dogs: what is the evidence for and against a cardiac cough? J Small Anim Pract 60: 139-145, 2019. https://doi.org/10.1111/jsap.12976

GANDEVIA SC, BUTLER JE, TAYLOR JL, CRAWFORD MR: Absence of viscerosomatic inhibition with injections of lobeline designed to activate human pulmonary C fibers. J Physiol 511: 289-300, 1998. https://doi.org/10.1111/j.1469-7793.1998.289bi.x

GIRSKY MJ, CIRLEY JM: Images in cardiovascular medicine. Cough cardiopulmonary resuscitation revisited. Circulation 114: e530-e531, 2006. https://doi.org/10.1161/circulationaha.106.620773

HARGREAVES M, CHANNON K: Mechanism of pacemaker induced cough. Br Heart J 71: 484-486, 1994. https://doi.org/10.1136/hrt.71.5.484

HART G, OLDERSHAW PJ, CULL RE, HUMPHREY P, WARD D: Syncope caused by cough-induced complete atrioventricular block. Pacing Clin Electrophysiol 5: 564-566, 1982. https://doi.org/10.1111/j.15408159.1982.tb02279.x

HASDEMIR C, MUSAYEV O, KEHRIBAR DY, KARTAL Y, CAN LH: Chronic cough and tachycardia-induced cardiomyopathy in a patient with idiopathic frequent, monomorphic premature ventricular contractions. Pacing Clin Electrophysiol 36: e156-e158, 2013. https://doi.org/10.1111/j.1540-8159.2011.03236.x

IRANI F, SANCHIS J: Inspiration- and cough-induced atrioventricular block. Can Med Assoc J 105: 735-756, 1971.

IRWIN RS, FRENCH CL, CHANG AB, ALTMAN KW. CHEST Expert cough panel: classification of cough as a symptom in adults and management algorithms: CHEST guideline and expert panel report. Chest 153: 196209, 2018. https://doi.org/10.1016/j.chest.2016.03.014

JAVORKOVA N, VARECHOVA S, PECOVA R, TATAR M, BALAZ D, DEMETER M, HYRDEL R, KOLLARIK M: Acidification of the esophagus acutely increases the cough sensitivity in patients with gastrooesophageal reflux and chronic cough. Neurogastroenterol Motil 20: 119-124, 2008. https://doi.org/10.1111/j.13652982.2007.01020.x

KALLA M, HERRING N, PATERSON DJ: Cardiac sympatho-vagal balance and ventricular arrhythmia. Auton Neurosci 199: 29-37, 2016. https://doi.org/10.1016/j.autneu.2016.08.016

KARDOS P, BERCK H, FUCHS KH, GILLISSEN A, KLIMEK L, MORR H, PFEIFFER-KASCHA D, SCHULTZEWERNINGHAUS G, SITTER H, VOSHAAR T, WORTH H: German Respiratory Society for diagnosis and treatment of adults suffering from acute or chronic cough. Guidelines of the German Respiratory Society for diagnosis and treatment of adults suffering from acute or chronic cough. Pneumologie 64: 701-711, 2010. https://doi.org/10.1055/s-0030-1255526

KOLLARIK M, BROZMANOVA M: Cough and gastroesophageal reflux: insights from animal models. Pulm Pharmacol Ther 22: 130-134, 2009. https://doi.org/10.1016/j.pupt.2008.12.017

KOLLARIK M, RU F, BROZMANOVA M: Vagal afferent nerves with the properties of nociceptors. Auton Neurosci 153: 12-20, 2010. https://doi.org/10.1016/j.autneu.2009.08.001

KRYŃSKI T, STEC S, MAKOWSKA E, SWIATKOWSKI M, SZYMOT J, KUŁAKOWSKI P: Atrial infarction or ischaemia as the cause of atrial pacing failure in a patient with acute myocardial infarction. Kardiol Pol 65: 1381-1383, 2007.

LAI K, SHEN H, ZHOU X, QIU Z, CAI S, HUANG K, WANG Q, WANG C, LIN J, HAO C, KONG L, ZHANG S, CHEN Y, LUO W, JIANG M, XIE J, ZHONG N: Clinical practice guidelines for diagnosis and management 
of cough-Chinese Thoracic Society (CTS) Asthma Consortium. J Thorac Dis 10: 6314-6351, 2018. https://doi.org/10.21037/jtd.2018.09.153

LEE D, BELDNER S, POLLARO F, JADONATH R, MACCARO P, GOLDNER B: Cough-induced heart block. Pacing Clin Electrophysiol 22: 1270-1271, 1999. https://doi.org/10.1111/j.1540-8159.1999.tb00615.X

LEE LY, PISARRI TE: Afferent properties and reflex functions of bronchopulmonary C-fibers. Respir Physiol 125: $47-$ 65, 2001. https://doi.org/10.1016/s0034-5687(00)00204-8

LO MAURO A, ALIVERTI A: Blood shift during cough: negligible or significant? Front Physiol 9: $501,2018$. https://doi.org/10.3389/fphys.2018.00501

MAZZONE SB: An overview of the sensory receptors regulating cough. Cough 1: 2, 2005. https://doi.org/10.1186/1745-9974-1-2

MCLACHLAN CS, YOW SZ, AL-ANAZI M, EL OAKLEY RM: Letter by McLachlan et al regarding article, "Cough cardiopulmonary resuscitation revisited". Circulation 115: e460, 2007. https://doi.org/10.1161/circulationaha.106.672204

NIIMI A, KIHARA Y, SUMITA Y, OKANO Y, TAMBARA K, FUJITA M: Cough reflex by ventricular premature contractions. Int Heart J 46: 923-926, 2005. https://doi.org/10.1536/ihj.46.923

ODEH M, OLIVEN A: A man who coughed for 15 years before a doctor took his pulse. Lancet 348: 378 , 1996. https://doi.org/10.1016/s0140-6736(96)03432-0

OMORI I, YAMADA C, INOUE D, KATSUME H, IJICHI H: Tachyarrhythmia provoked by coughing and other stimuli. Chest 86: 797-799, 1984. https://doi.org/10.1378/chest.86.5.797

OZTURK S, YETKIN E: An innocent etiology of chronic cough: premature atrial contraction. Int J Cardiovasc Res 5: 6, 2016. https://doi.org/10.4172/2324-8602.1000290

PACHON JC, PACHON EI, PACHON JC, LOBO TJ, PACHON MZ, VARGAS RN, JATENE AD: "Cardioneuroablation"--new treatment for neurocardiogenic syncope, functional AV block and sinus dysfunction using catheter RF-ablation. Europace 7: 1-13, 2005. https://doi.org/10.1016/j.eupc.2004.10.003

PATBERG KW, DE GROOT JR, REESINK HJ, SNIJDERS D, STERK PJ, BEL EHD: Cardiac arrhythmia induced cough: demonstrable but not clinically significant in chronic cough. Am J Respir Crit Care Med 185: A5847, 2012. https://doi.org/10.1164/ajrccm-conference.2012.185.1_meetingabstracts.a5847

PONIKOWSKI P, VOORS AA, ANKER SD, BUENO H, CLELAND JG, COATS AJ, FALK V, GONZÁLEZJUANATEY JR, HARJOLA VP, JANKOWSKA EA, JESSUP M, LINDE C, NIHOYANNOPOULOS P, PARISSIS JT, PIESKE B, RILEY JP, ROSANO GM, RUILOPE LM, RUSCHITZKA F, RUTTEN FH, VAN DER MEER P: Authors/Task Force Members, Document Reviewers: 2016 ESC Guidelines for the diagnosis and treatment of acute and chronic heart failure: The Task Force for the diagnosis and treatment of acute and chronic heart failure of the European Society of Cardiology (ESC). Developed with the special contribution of the Heart Failure Association (HFA) of the ESC. Eur J Heart Fail 18: 891-975, 2016. https://doi.org/10.1002/ejhf.592

RAJ H, SINGH VK, ANAND A, PAINTAL AS: Sensory origin of lobeline-induced sensations: a correlative study in man and cat. J Physiol 482(Pt 1): 235-246, 1995. https://doi.org/10.1113/jphysiol.1995.sp020513

REISIN L, BLAER Y, JAFARI J, MANOACH M: Cough-induced nonsustained ventricular tachycardia. Chest 105: 1583-1584, 1994. https://doi.org/10.1378/chest.105.5.1583

RESUSCITATION COUNCIL (UK): Statement on cough CPR [Accessed 22 September 2019] https://www.resus.org.uk/cpr/statement-on-cough-cpr

RUCKDESCHEL ES, WOLFEL E, NGUYEN DT: A Case of cough-induced ventricular tachycardia in a patient with a left ventricular assist device. Card Electrophysiol Clin 8: 165-167, 2016. https://doi.org/10.1016/j.ccep.2015.10.019

RYBAK IA, O'CONNOR R, ROSS A, SHEVTSOVA NA, NUDING SC, SEGERS LS, SHANNON R, DICK TE, DUNIN-BARKOWSKI WL, OREM JM, SOLOMON IC, MORRIS KF, LINDSEY BG: Reconfiguration of the pontomedullary respiratory network: a computational modeling study with coordinated in vivo experiments. J Neurophysiol 100: 1770-1799, 2008. https://doi.org/10.1152/jn.90416.2008

SACHER F, MONAHAN KH, THOMAS SP, DAVIDSON N, ADRAGAO P, SANDERS P, HOCINI M, TAKAHASHI Y, ROTTER M, ROSTOCK T, HSU LF, CLÉMENTY J, HAÏSSAGUERRE M, ROSS DL, 
PACKER DL, JAÏS P: Phrenic nerve injury after atrial fibrillation catheter ablation: characterization and outcome in a multicenter study. J Am Coll Cardiol 47: 2498-2503, 2006. https://doi.org/10.1016/j.jacc.2006.02.050

SAITO D, MATSUNO S, MATSUSHITA K, TAKEDA H, HYODO T, HARAOKA S, WATANABE A, NAGASHIMA H: Cough syncope due to atrio-ventricular conduction block. Jpn Heart J 23: 1015-1020, 1982. https://doi.org/10.1536/ihj.23.1015

SAKIHARA E, KURIYAMA A, OKABE K, IKEGAMI T: An unexpected cause of chronic cough in a young woman: Tachycardia-induced cardiomyopathy. Am J Emerg Med 37: 563.e5-563.e7, 2019. https://doi.org/10.1016/j.ajem.2018.12.014

SELLICK H, WIDDICOMBE JG: The activity of lung irritant receptors during pneumothorax, hyperpnoea and pulmonary vascular congestion. J Physiol 203: 359-381, 1969. https://doi.org/10.1113/jphysiol.1969.sp008868

SHARPEY-SCHAFER EP: Effects of coughing on intrathoracic pressure, arterial pressure and peripheral blood flow. J Physiol 122: 351-357, 1953. https://doi.org/10.1113/jphysiol.1953.sp005004

SHEN WK, SHELDON RS, BENDITT DG, COHEN MI, FORMAN DE, GOLDBERGER ZD, GRUBB BP, HAMDAN MH, KRAHN AD, LINK MS, OLSHANSKY B, RAJ SR, SANDHU RK, SORAJJA D, SUN BC, YANCY CW: 2017 ACC/AHA/HRS Guideline for the evaluation and management of patients with syncope: executive summary: a report of the American College of Cardiology/American Heart Association Task Force on clinical practice guidelines and the Heart Rhythm Society. J Am Coll Cardiol 70: 620-663, 2017. https://doi.org/10.1161/cir.0000000000000498

SHEPHERD JT: The lungs as receptor sites for cardiovascular regulation. Circulation 63: 1-10, 1981. https://doi.org/10.1161/01.cir.63.1.1

SHEPHERD JT: The heart as a sensory organ. J Am Coll Cardiol 5 (6 Suppl): 83B-87B, 1985. https://doi.org/10.1016/s0735-1097(85)80533-7

SHIVKUMAR K, AJIJOLA OA, ANAND I, ARMOUR JA, CHEN PS, ESLER M, DE FERRARI GM, FISHBEIN MC, GOLDBERGER JJ, HARPER RM, JOYNER MJ, KHALSA SS, KUMAR R, LANE R, MAHAJAN A, PO S, SCHWARTZ PJ, SOMERS VK, VALDERRABANO M, VASEGHI M, ZIPES DP: Clinical neurocardiology defining the value of neuroscience-based cardiovascular therapeutics. J Physiol 594: 39113954, 2016. https://doi.org/10.1113/jp271870

STEC S, DABROWSKA M, ZABORSKA B, BIELICKI P, MASKEY-WARZECHOWSKA M, TARNOWSKI W, CHAZAN R, KULAKOWSKI P: Premature ventricular complex-induced chronic cough and cough syncope. Eur Respir J 30: 391-394, 2007. https://doi.org/10.1183/09031936.00062606

STEC SM, GRABCZAK EM, BIELICKI P, ZABORSKA B, KRENKE R, KRYŃSKI T, DĄBROWSKA M, DOMAGAŁA-KULAWIK J, DOMERACKA-KOŁODZIEJ A, SIKORSKA A, KUŁAKOWSKI P, CHAZAN R: Diagnosis and management of premature ventricular complexes-associated chronic cough. Chest 135: 15351541, 2009. https://doi.org/10.1378/chest.08-1814

TAKAZAWA T, IKEDA K, KANO O, KABUKI T, KAWABE K, IWASAKI Y: A case of sinus arrest and post-hiccup cough syncope in medullary infarction. J Stroke Cerebrovasc Dis 23: 566-571, 2014. https://doi.org/10.1016/j.jstrokecerebrovasdis.2013.04.016

TRETHEWEY SP: 'Cough CPR': Misinformation perpetuated by social media. Resuscitation 133: e7-e8, 2018. https://doi.org/10.1016/j.resuscitation.2018.10.003

WALDMANN V, COMBES N, NARAYANAN K, SHARIFZADEHGAN A, BOUZEMAN A, BEGANTON F, COMBES S, ALBENQUE JP, BOVEDA S, MARIJON E: Cough Syncope. Am J Med 130: e295-e296, 2017. https://doi.org/10.1016/j.amjmed.2017.01.050

WANG X, LI Z, WANG J, HE B: The application of catheter ablation in a rare case with coughing-induced supraventricular tachyarrhythmias. Clinical Case Rep 5: 2133-2135, 2017. https://doi.org/10.1002/ccr3.1078

WEI JY, GREENE HL, WEISFELDT ML: Cough-facilitated conversion of ventricular tachycardia. Am J Cardiol 45: 174-176, 1980. https://doi.org/10.1016/0002-9149(80)90235-0

WEI JY, HARRIS WS: Heart rate response to cough. J Appl Physiol Respir Environ Exerc Physiol 53: 1039-1043, 1982. https://doi.org/10.1152/jappl.1982.53.4.1039 
WEI JY, ROWE JW, KESTENBAUM AD, BEN HAIM S: Post-cough heart rate response: influence of age, sex, and basal blood pressure. Am J Physiol 245: R18-R24, 1983. https://doi.org/10.1152/ajpregu.1983.245.1.r18

WIDDICOMBE JG: Neurophysiology of the cough reflex. Eur Respir J 8: 1193-1202, 1995. https://doi.org/10.1183/09031936.95.08071193 